\title{
Diagnostics of socio-pedagogical trends in the development of students in a professional educational organization
}

\author{
Y.N. Petrov ${ }^{1 *}$, O.N. Filatova ${ }^{2}$, and M.V. Grinina ${ }^{3}$ \\ ${ }^{1}$ Nizhny Novgorod Institute of Education Development, Nizhny Novgorod, Russia \\ ${ }^{2}$ Nizhny Novgorod State Pedagogical University. Kozma Minin, Nizhny Novgorod, Russia \\ ${ }^{3}$ Nizhny Novgorod Institute of Education Development, Nizhny Novgorod, Russia
}

\begin{abstract}
The article under consideration presents the diagnosis of social and pedagogical trends in the development of students in a professional educational organization. A comparative analysis of the diagnostic experiment is given. The experiment carried out within the framework of the study showed a significant shift in the spiritual, moral and patriotic value orientations of students to a pragmatic orientation. In the pedagogical diagnostics, which was carried out within the framework of the study, the object was the spiritual, moral and patriotic orientations of students, which manifested themselves in various facts of their attitudes and behavior. This made it possible to track the development of students' civic engagement, since the diagnostic procedure is used to detect changes in the cause and disclose their manifestation in pedagogical practice. An experimental analysis of the problem under consideration has shown that modern conditions require the energetic entry of the individual into the spiritual space and the development of spiritual, moral and patriotic orientations, which are associated with the direction of the development of civic activity of the individual, the harmonization of humanity and pragmatism, becomes essential.
\end{abstract}

\section{A problem statement}

Divided into two levels, social and pedagogical diagnostics, on the one hand, presents generalized data for the design of generalized principles and actions to optimize the processes of teaching and upbringing with the adoption of managerial decisions, and on the other hand, it is the development of targeted models of educational activities and targeted programs in various areas of educational - educational work in a professional educational organization.

Naturally, not all socio-pedagogical diagnostics is monitoring. At the same time, almost any monitoring of the educational process in systemic sociological research can, in its evaluative basis, be basic for social and pedagogical diagnostics.

\footnotetext{
*Corresponding author: prof-ped.gpa@mail.ru
} 


\subsection{The objective of the work}

Many researchers in various fields of science have dealt with the problem of sociopedagogical trends in the development of students in a professional educational organization, but despite the existing theories and hypotheses, this problem has not been fully studied, it has many models and solutions, but takes on particular relevance in a modern digital society $[1,2]$.

Educators of vocational educational organizations note that the issues of training and education require a new interpretations in educational policy and $92.5 \%$ confirm the inseparability of teaching and education, and $29.4 \%$ of teachers believe that these functions should be performed by educational structures [3].

In our research, we relied on the works of domestic and foreign authors: R.M. Weiss, D.I. Feldstein, B.G. Ananiev, L.I. Bozhovich, A.V. Mudrik, D. Myers, V.A. Sukhomlinsky, A.A. Rean, A. Maslow and others [4-10]. The works of the above authors in the field of psychology, pedagogy and sociology are the basis from which further research and analysis of the experiments carried out in professional educational organizations proceeds.

\section{Results of the research}

Pedagogical diagnostics, in our study, will be considered as pedagogical activity aimed at studying and recognizing the state of objects (and subjects) of upbringing in order to cooperate with them and manage the upbringing process. In professional educational organizations today, the educational process has become more complex in content and intensity and requires a deep pedagogical understanding by teachers of the patterns of educational activity, principles, methods of teaching and upbringing. It should be noted that the age period of 16-22 years is characterized by a peak in the development of civic activity of the individual with a spiritual, moral and patriotic orientation, which undoubtedly affects the activities of a vocational and educational organization.

Educational vocational organizations believe that outside of work there is no development of a spiritual personality, and the research of G.I. Shchukina emphasize: "Students undergo a significant development of the consciousness of relations and the formation of their worldview, depending on the acquired system of knowledge and life experience" [11]. The main need of students is the need for communication [8] - this was shown in his research by A.V. Mudrik. With regard to his future, the student evaluates himself, and as L.S. Slavina: "In adolescence, students are already equipped with that personal neoformation (the ability to consciously set goals related to their future life and activities, and achieve these goals), which allows them to take a new internal position - the position of people who are looking into the future" [7].

Students are distinguished by a variety of interests and the stability of their goals, therefore N.D. Levitov notes: "In the orientation of the personality of young people, in comparison with adolescents, first of all, there is a greater awareness and selectivity of interests, a more pronounced and more thorough purposefulness, subordination of private goals to one dominant one, as well as an active willingness to fight to achieve this goal. Such purposefulness is associated with the formation of a world outlook in boys and girls and with the aggravation and great organization of the motives of behavior. "Youth age V.A. Krutetsky presented: "The age of romance, great daring, youthful dreams associated with the desire to devote one's strength to some big cause, the age of creative initiative" $[10,11]$.

It should be noted, as I.S. Kon: "Youthful maximalism, overestimation of assessments and claims often interfere with a correct, sober understanding of reality" [8]. As scientists 
note, this happens with grown-up students, but not yet adults, who are keen but not yet enthusiastic, informed, but not yet competent [7].

The formation and formation of personality in adolescence is considered as a complex age personality trait. Achieving mutual understanding among students leads, as B.T. Likhachev to various forms of communication: "There is a confidential conversation, and a philosophical debate, and various forms of assistance in individual creativity, and a direct or indirect expression of sympathy, empathy, the provision of moral support in business, and the expression of fundamental disagreement in case of divergence of views" [3].

Features characteristic of students of a professional educational organization are generated by the specifics of the educational institution itself, where students receive a profession. Activities of a professional educational organization is aimed at preparing a student for secondary education and acquiring a profession. Educational training center is transferred to the acquisition experience in technological practice and a system of professional and specialized knowledge and skills.

The change in the forms and content of education and upbringing distinguishes a professional educational organization from a general education school. Since the main function of a professional educational organization is the formation of the personality of a specialist, the main goal communication between teachers and students is subordinated, and provides then at a professional level, a system of relationships. In a professional educational organization, a heterogeneous age composition with an uneven psyche of development of students, and this leads to taking these features into account during the period of study. Of no small importance in fostering an active life position is the stimulation of scholarships for students. In professional educational organizations, there are teachers with academic degrees and titles that orient students to research activities. The vocational school demanded the revival of the institution of supervision, this is especially felt in the first year of study, when adapting to the new student life of students. According to the results of the study, $76 \%$ of the respondents supported the idea of supervising the study group [12].

In the life of students enrolled in a professional educational organization, a new stage of age development is presented. They can reach the maximum of their development of the properties of higher mental functions: memory, attention, perception, speech, thinking, feelings and emotions. According to B.G. Ananyeva: "This stage of life is the most favorable for education and professional training" [6]. The influence of the new state in the surrounding space on development of the student's personality. For the first time, a student makes a social choice - he has decided on the choice of a specialty. Educational and professional activity becomes the leading one for the student, since during it the main interests, skills, and abilities are formed, a certain experience is acquired with the development of moral ideals. It should be noted that the development of the student's personality occurs in several directions, taking into account the future specialist of professional education.

The dialectic of the development of the student's personality is the transition from the external to the internal, self-movement, active work on oneself. "Integration increasing in scale and level, the formation of substructures and their complicating synthesis" [6], as B.G. Ananiev. Main the contingent of students in a professional educational organization is made up of secondary school graduates, and some of them are from other cities, who turn out to be divorced from their parents with a great development of independence.

The social environment and society as a whole have an impact on the formation and development of the student's personality, therefore, drunkenness and drug addiction are becoming more common. The drug addiction rate among adolescents is about twice that of the general population. The main reasons for the development of drug addiction in the educational space are the following:

- inability to control his behavior; 
- personal problems and worries;

- curiosity and curiosity in [13].

Drug addiction in the educational space is a drug business for students, an extremely attractive business. Particular attention should be paid to the upbringing of such a group of students, as well as to the development of their civic activity, spiritual, moral and patriotic orientation, which is the dictates of the times and is explained by the following reasons:

- how future specialists of society are assigned the role and place of students of professional educational organization as a source of recruiting;

- age qualities of students.

Characteristic features of adolescence in a professional educational organization in the conditions of unity of interests are the formation of future specialists with professional education.

In the pedagogical diagnostics, which was carried out within the framework of the study, the object was the spiritual, moral and patriotic orientations of students, which manifested themselves in various facts of their attitudes and behavior. This made it possible to track the development of civic activity of students, since the diagnostic procedure is used to detect changes in the cause and disclose their manifestation in pedagogical practice.

The change caused in the state by the processes of democratization and humanization of social relations has a sharp impact on the consciousness of students with a reorientation of their personal attitudes towards practice and enterprise.

An essential prerequisite for spiritual, moral and patriotic orientation for managing the civic activity of students is the study of students' abilities to think in terms of morality, since in order to determine their life guidelines, students must clearly understand their essence. $88 \%$ of the surveyed students correctly grasp the essence of the analyzed concepts, which confirms the presence of a certain life experience and a conscious choice of spiritual, moral and patriotic attitudes [14].

The analysis of studies confirms the trend of developing corrosion - the hobby of students for smoking, drunkenness, drug addiction, foul language, since smoking has become almost a mass phenomenon (73\%). Twenty years later, the enrollment of students was two times lower (30.8\%) [15], and the use of alcohol has also doubled (44\% and $22 \%$ ) among students.

Experimental studies have made it possible to highlight an interesting way of psychological influence on students with bad habits, which is not fashionable. Highlighting this idea before the Russian psychologists D.I. Feldstein [5] formulates the problem as follows: "How to instill (indirectly, of course, on an unconscious level) to adolescents, boys, girls that it is not fashionable to use drugs, or to find another, but necessarily working, and not a proclaimed method in the general system of means, conditions prevention and correction of deviations in personal development, overcoming various forms of anxiety, cruelty, aggressiveness, chemical addictions"[4, 5].

The analysis shows that $79.0 \%$ of students understand the dangers of drug use. There are alternatives to drug addiction in modern society, as there is a clear analysis of the reasons for the use of this infection.

\section{Conclusions}

Analysis of the problem of the development of students with spiritual, moral and patriotic value orientations in a professional educational organization according to the analysis of theoretical and experimental research allowed us to draw significant conclusions:

1. The development of students with spiritual, moral and patriotic value orientations in the training process is supposed to carry out purposefully organized activities that allow the student to become a subject of conscious educational activity. 
2. The developed design model for the development of civic engagement of students with spiritual, moral and patriotic value orientations during vocational training in a professional educational organization should include the following elements: goal, theoretical and conceptual approaches, principles of personality development in the educational activities of a professional educational organization; learning content through the implementation of components; didactic and organizational-pedagogical conditions; forms of organizing the educational space of learning. This model allowed us to get the result: the harmonious development of the individual with spiritual, moral and patriotic value orientations $[16,17]$.

3. The methodological basis of the experimental research was a conscious spiritual, moral and patriotic orientation of students about systemic activity.

4. Spiritual, moral and patriotic value orientations are systemic and complex in the development of civil activity of future professional specialists.

5. The problem of finding effective ways to develop the spiritual revival of society is inevitably actualized, since domestic legislation fixed the need of Russian society for the development of a socially active, moral personality, which coincides with the real goal of spiritual, moral and patriotic orientation.

6. Determination of priority accents of thinking of students with an overweight of value coordinates - this is the specificity of a professional educational organization. An experimental analysis of the problem under consideration has shown that modern conditions require the energetic entry of the individual into the spiritual space and the development of spiritual, moral and patriotic orientations, which are associated with the direction of the development of civic activity of the individual, the harmonization of humanity and pragmatism, becomes essential.

7. The socio-pedagogical diagnostic experiment showed a significant shift in the spiritual, moral and patriotic orientations of students to a pragmatic orientation, and a significant result of this experiment was the achievement of harmony of spiritual, moral and patriotic attitudes by students.

8. The results of experimental research confirmed the effectiveness and necessity of pedagogical development of civic activity of students with spiritual, moral and patriotic value orientations, and this made it possible to significantly correct the spiritual, moral and patriotic orientations of civic activity of students [18-20].

\section{References}

1. S.M. Markova, S.A. Tsyplakova, E.P. Sedykx, A.V. Khizhnaya, O.N. Filatova, Forecasting the development of professional education, Lecture Notes in Networks and Systems, 91, 452-459 (2020)

2. Y.N. Petrov, O.N. Filatova, Professional education in the modern digital space, Nizhny Novgorod education, 1, 30-33 (2019)

3. Y. Petrov, A. Petrov, M. Bulaeva, Management and pedagogical activity of the head of a professional educational organization to improve the quality of education (2017)

4. O.S. Gazman, R.M. Weiss, N.B. Krylova, New values of education (1995)

5. D.I. Feldstein, Psychology of human development as a person (2005)

6. B.G. Ananiev, Selected psychological works (2005)

7. L.I. Bozhovich, L.S Slavina. The mental development of the student and his upbringing, 140 (2005)

8. A.V. Mudrik, Modern high school student (2007) 
9. A.A. Rean, Zh.K. Dandareva, V.A. Prokofieva, Social orphanhood in modern Russia (2002)

10. L.A. Hjelle, D.J. Ziegler, Personaliti Theories (2011)

11. D. Myers, Social Psychology (2006)

12. A.Y. Petrov, Development of early career guidance activities in the vocational education system (2019)

13. M.V. Grinina, Professionalism of graduates of professional educational organizations of a small tow (2019)

14. Y.N. Petrov, M.V. Firsov, O.N. Filatova, Cognitive direction of development of digitalization of vocational education, Bulletin of the Baltic State Academy of Fishing Fleet, 2(52), 7-11 (2020)

15. Y. Petrov, I. Kryzhanovskaya, The basis for supporting the professional selfdetermination of future specialists (2016)

16. O.N. Filatova, G.A. Gribina, E.L. Ermolaeva, Educator of vocational training in the future digital educational space, Problems of modern teacher education, 67(1), 245248 (2020)

17. M.P. Prohorova, O.I. Vaganova, Technology of educational events in Russian and foreign educational practice, Minin University Bulletin, 7(4) (2019)

18. Y.N. Petrov, A.Y. Petrov, N.S. Petrova, N.V. Syrova, O.N. Filatova, Change of the Level of Working Capacity of a Student in the System of Professional Education Under Mental Load, Lecture Notes in Networks and Systems, 129, 925-932 (2020)

19. Y. Petrov, N. Barmin, A. Petrov, M. Bulaeva, Dependence of the teacher soverall work capacity on the professional expertise, International journal of environmental \& science education, 11(16), 9079-9091 (2016)

20. O.N. Filatova, M.V. Firsov, D.L. Morozov, The content of the pedagogical model of support for the professional self-determination of learning youth in a distance format, Bulletin of the Baltic State Academy of Fishing Fleet, 4(54), 22-27 (2020) 